\title{
Erratum: Research on the FE and semi-analytical solution with the blade-casing rub-impact dynamical system
}

\section{Chaofeng $\mathrm{Li}^{1}$, Houxin $\mathrm{She}^{2}$, Qiansheng Tang ${ }^{3}$, Bangchun Wen ${ }^{4}$}

School of Mechanical Engineering and Automation, Northeastern University, Shenyang, 110819, China ${ }^{1}$ Corresponding author

E-mail: ${ }^{1}$ chaof.li@gmail.com, ${ }^{2}$ houxinshe@sina.com, ${ }^{3}$ qiansh_tang@163.com, ${ }^{4}$ bcwen1930@vip.sina.com DOI https://doi.org/10.21595/jve.2018.20366

Check for updates

Copyright $(2018$ JVE International Ltd. This is an open access article distributed under the Creative Commons Attribution License, which permits unrestricted use, distribution, and reproduction in any medium, provided the original work is properly cited.

\section{Publisher's note regarding paper}

Li Chaofeng, She Houxin, Tang Qiansheng, Wen Bangchun Research on the FE and semi-analytical solution with the blade-casing rub-impact dynamical system. Journal of Vibroengineering, Vol. 17, Issue 7, 2015, p. 3438-3452.

\section{The description of the correction}

Fig. 1(a) from the Ref. [13] was used, but the reference was not cited in figure title and the copyright was missing in the original article and finally approved (after the acceptance) by the authors.

The revised figure title is as follows:

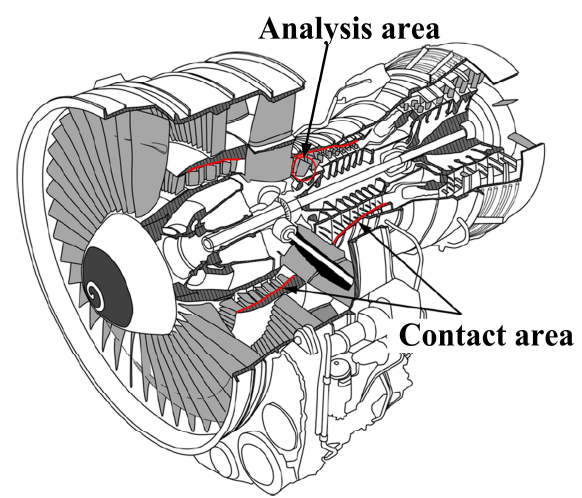

a)
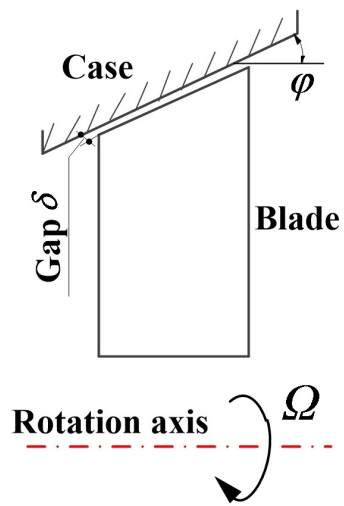

b)

Fig. 1. Schematic of rotating blades force environment: a) Cut-view of an aircraft engine with sensitive contact areas [13] (https://doi.org/10.1115/1.4006446; Copyright (C) 2012 by American Society of Mechanical Engineers); b) Schematic of blade-casing 